LITERATURA 



\title{
MENÉNDEZ PELAYO Y LA HETERODOXIA: EL CASO DE GRACILIANO AFONSO
}

\author{
Antonio Becerra Bolaños
}

\begin{abstract}
RESUMEN
El eminente polígrafo español Marcelino Menéndez Pelayo (1856-1912) mostró gran interés por la obra del doctoral de la catedral de Canarias Graciliano Afonso (1775-1861), fundamentalmente en su vertiente de traductor como lo demuestra la correspondencia que aparece recogida en su Epistolario y que fue publicada entre 1985 y 1991. Un rastreo por las páginas de su voluminoso epistolario nos da una idea de cómo el investigador logró hacer acopio de una documentación tan vasta no sólo de la obra del doctoral, sino de otros autores canarios.

Palabras clave: Menéndez Pelayo-Marcelino, Afonso-Graciliano, Canarias, traducción, siglo XIX.
\end{abstract}

\begin{abstract}
The eminent Spanish polygraph Marcelino Menéndez Pelayo (1856-1912) showed great interest in the literary works Graciliano Afonso (1775-1861), of doctoral of Canary Islands Cathedral, primarily in its aspect of translator as shown in the correspondence that set out in his letters and which was published between 1985 and 1991. A crawl through the pages of his voluminous correspondence gives us an idea of how the researcher was able to garner so vast documentation not only of the work of doctoral, but other authors from Canary Islands.

Keywords: Menéndez Pelayo-Marcelino, Afonso-Graciliano, Canary Islands, translation, $19^{\text {th }}$ century.
\end{abstract}

Graciliano Afonso es un personaje controvertido en las literaturas hispánicas; constituye una figura, al igual que sucede con el italiano Giambattista Casti -cuyas Novelle galanti tradujo ${ }^{1}$ y al que Menéndez Pelayo también dedicará algunas páginas-. De talante político definidamente liberal -recuérdese que fue diputado a Cortes durante el Trienio Liberal (1820-1823)-, lo que le valió constantes choques con las autoridades eclesiásticas y políticas más conservadoras ${ }^{2}$, hay que unir la más que segura filiación a la masonería; de hecho, era conocido por el sobrenombre de Morlay (Gil Novales 1991).

Dr. Antonio Becerra Bolaños. Profesor invitado. Lengua y Literatura Española. Universidad Politécnica Estatal del Carchi, Ecuador.

Correo electrónico: becerrabol@gmail.com

Recepción: 24- 10- 2012

Aceptación: 21- 02- 2013 
La labor de Afonso es además sospechosa por la situación en que se encuentran las Islas Canarias en cuanto a la difusión de las ideas, en el sentido de que estas circulaban casi siempre de forma manuscrita y llegaban a círculos restringidos. De ahí el esfuerzo de Afonso. Como afirma Eugenio Padorno: "La pobreza cultural de las Islas obligó a Afonso a teñir de didactismo el amplio espectro de su producción, actitud que debe entenderse como el rasgo filantrópico de un ilustrado" (2000: 56). La ciudad de Las Palmas de Gran Canaria, por ejemplo, en el siglo XIX tiene una población que no alcanza las quince mil almas, de las cuales el setenta por ciento no sabe leer ni escribir. Marín subraya esta dramática circunstancia que se da en las Islas:

Puede admitirse que a lo largo de la centuria pasada, y en los primeros veinte años de la presente, casi
toda la población de Canarias Orientales desconocía los más mínimos principios de lectura y escritura.
El nivel de instrucción era bajísimo y ésta se encontraba ligada solamente a unos grupos sociales
muy determinados: el Clero, Ejército, comerciantes, etc. Y evidentemente, la clase social dominante,
poseedora de la tierra. Nada menos que el 80 por 100 de la población se podía catalogar como analfabeta
en 1887. Ni siquiera en los jóvenes los índices de analfabetismo aumentan de un modo notable, lo cual
quiere decir que el nivel de escolarización debía ser bajísimo. (1997: 491)

En ese contexto se desarrolla la vida del doctoral. La empresa intelectual de Afonso está marcada por estas circunstancias, que lo obligan, por un lado, a definirse favorablemente por la Ilustración, opción por la que se decantarán los intelectuales que le sigan. Y, por otro, aquellas mismas circunstancias lo obligarían a abandonar la posibilidad de desarrollar, a priori, una obra de miras poéticas mayores. El poeta sabe que no es esa la época para la que están destinados muchos de sus textos.

La influencia que Graciliano Afonso ejerce en los escritores y pensadores de la segunda mitad del siglo XIX es indudable, tanto por el interés que muestra en incorporar Canarias al pensamiento occidental mediante sus traducciones como por salvaguardar el acervo cultural canario, lo que le lleva, en sus obras, a glosar palabras del guanche. La enunciación teórica y poética que el doctoral realiza sobre el Teide hará que a partir de ese momento comience a ser considerado este motivo como uno de los centrales de la literatura canaria. Su postura ante los episodios de la conquista, que tratará en sus poemas sobre las leyendas canarias, lo sitúa dentro de la categoría de precursor -“adalid”, para María Rosa Alonso (1952: 461)- de lo que se denominará vianismo, en tanto que sentimiento aglutinador de una facción de la literatura canaria que englobará a románticos como José Plácido Sansón, Victoria Ventoso o Nicolás Estévanez y, posteriormente, a la llamada escuela regionalista de La Laguna. Hemos de tener en cuenta, además, su adhesión a los ideales de La Aurora (1847-1848), revista que nace con la pretensión de rescatar del olvido los prototipos humanos de la historia canaria, en la que interviene, aunque no se puede considerar, por razones que expondré más adelante, que su participación en esta efímera empresa sea una adhesión plena. Su influencia, no obstante, no se limita sólo a aquellos escritores. Como afirma Eugenio Padorno, al abordar el "programa literario" al que se adscribe el doctoral, "Afonso sabía que él por razones biológicas no podía ser el poeta que, tras los pasos de Cairasco y Viana, refundara la lírica canaria, pero con su gesto espera haberle indicado el camino" (2003: 158).

Afonso, a través de su labor didáctica en el seminario y en el colegio San Agustín, establecerá una conciencia del paisaje y de la tradición que vincula a éste con la historia que llegará hasta los autores del siglo XX.

Señalaba recientemente Álvarez Barrientos, a propósito de Marcelino Menéndez Pelayo, los prejuicios que pesaban y pesan aún sobre el fundador de la crítica española, en buena parte producto de una instrumentalización ideológica: 


\begin{abstract}
A la vista del desarrollo de las diversas materias que trató [...] parece conveniente acercarse a su obra sin todo aquello que la envuelve, sin los prejuicios de unos y de otros, sin juzgar su persona, ni a su obra por la persona, como hizo él tantas veces en los Heterodoxos, pero no en los otros trabajos. Convendría no reproducir sus errores e intentar valorar su aportación desde su contexto histórico. Este acercamiento, que aquí se ha intentado, depara sorpresas, porque Menéndez Pelayo fue un historiador como otros importantes de su época a los que, a diferencia de a él, no se les acusa de sus arbitrariedades, ni tampoco se les exige que renuncien a sus creencias ni a su falta de relativismo cultural, algo que aún no existía en la época. (2012: 2)
\end{abstract}

Nuestra intención es ofrecer un acercamiento a la posición crítica que adoptó el polígrafo ante la heterodoxia que representaba Graciliano Afonso, que pudo haber pesado a la hora de que su obra se difundiera. En este sentido, un análisis de su Epistolario ofrece la perspectiva precisa para conocer cuál era la consideración que le merecía la obra del doctoral apenas unas décadas después de su fallecimiento. Para ello, asimismo, hemos de tener en cuenta los juicios que vierte sobre él en sus obras. En el año 1879, en su "Traductores españoles de la Eneida" del tomo X de la Biblioteca Clásica Española (Eneida, traducida en versos castellanos por Miguel Antonio Caro, tomo II), Menéndez Pelayo da noticia de la traducción y transcribe parte del prólogo del doctoral a las odas de Anacreonte.

Más tarde, en el tomo III de su Historia de las ideas estéticas (1883), Menéndez Pelayo introduce, en el capítulo III ("Desarrollo de la preceptiva literaria durante la segunda mitad del siglo XVIII y primeros años del XIX"), una prolija nota donde establece una suerte de inventario sobre los textos de crítica literaria que se dan en el periodo en cuestión. Entre las obras citadas, refiere aquellas que, de su propia biblioteca, "bastante copiosa en este género de literatura, se nos ofrecen todavía los siguientes, de que no hemos hecho mérito por no haber encontrado ocasión oportuna" (1985: 316). En esta nómina, incluye el Ensayo sobre la crítica, de Alexander Pope, en la traducción de Graciliano Afonso, de la que ofrece los siguientes datos:

\footnotetext{
Versión en endecasílabos asonantados flojos en general e insonoros. El traductor fue don Graciliano Afonso, doctoral de Canarias, infatigable versificador y humanista, que puso en castellano con poco numen todas las obras de Virgilio ${ }^{3}$, la Poética de Horacio, las odas de Anacreonte, el poemita Hero y Leandro, de Museo, el Rizo robado de Pope, el ditirambo de Dryden, y no sé cuántas poesías más. Su afición a los versos era tan grande como infortunada, sólo comparable con la de su paisano Viera y Clavijo. El Ensayo sobre la crítica va acompañado de notas útiles, unas originales, y otras estractadas de los comentadores ingleses de Pope. (1985: 318)
}

Un año antes, en 1882, el investigador, cuya fama, como se sabe, le había proporcionado la posibilidad de contar con fuentes manuscritas de primera mano, había ya realizado gestiones para obtener la primera obra publicada por el doctoral (Puerto Rico, 1838): la traducción de Anacreonte y de Museo, libro en el que se incluía El beso de Abibina. Así lo certifica la carta enviada por Eladio J. Vega, desde San Germán (Puerto Rico), en agosto de 1882 (V, carta n. ${ }^{\circ}$ 352), que hace llegar al investigador por mediación de Miguel Sánchez Pesquera desde Mayagüez (Venezuela); antes de lo cual, hará copia del tomo en cuestión. Años más tarde, Sánchez Pesquera se lamentará de no haber podido tener acceso a las traducciones de Pope realizadas por Graciliano Afonso para su Antología de líricos ingleses y angloamericanos.

En la presente obra, puede notarse deficiencia de poetas de los siglos XVI y XVII; pero téngase en cuenta que nuestro propósito ha sido, más que formar una antología completa, brindar una colección donde no falte ningún traductor español o hispanoamericano, y creemos haberlo conseguido, pues a sabiendas sólo ha escapado a nuestra pesquisa El rizo robado, de Pope, traducido por D. Graciliano Alfonso [sic], doctoral de Canarias, a principios del pasado siglo, y uno o más cantos de Childe Harold, de Byron, por el venezolano Arístides Calcaño (1915: 54). 
Sánchez Pesquera proporcionará datos curiosos sobre "el cuerpo del delito", como él lo define, para quien las iniciales que aparecen en la portada del libro, "D. de C.", no significan "Deán de Catedral" (el autor no considera la posibilidad de que sea "Doctoral de Canarias"); sino, escribe, "Desterrado de Canarias", deportado por sus opiniones liberales como lo revela su anacreóntica el "Canario" (V, carta n. ${ }^{\circ}$ 358). De la obra en cuestión escribirá en su Historia de la poesía hispano-americana:

\footnotetext{
La primera producción de amena literatura publicada en la isla [Puerto Rico], y rarísima por cierto, hasta el punto de no consignarse en la única Bibliografía Puerto-Riqueña que tenemos, es una traducción de las Odas de Anacreonte y del poemita de Museo Amores de Leandro y Hero, que juntamente con una colección de 27 anacreónticas originales, las cuales llevan el título común de El beso de Abibina, publicó en 1838 un clérigo helenista de las Islas Canarias, a quien sus ideas liberales, manifestadas cuando fue diputado a Cortes en el periodo constitucional del 1820 al 23, habían llevado a emigrar a la isla de Trinidad de Barlovento. (1911: 336)
}

Sánchez Pesquera le enviará otra carta (V, carta n. ${ }^{\circ}$ 367) en la que le dará más datos sobre el doctoral (en la edición del Epistolario se pone por error que "estaban dedicadas a Dn. José Junill [sic]", cuando quien aparece en el texto es Turull). Menéndez Pelayo entonces recurrirá a Diego Mesa, en Las Palmas de Gran Canaria, para obtener mayor información y bibliografía sobre el doctoral (VI, carta n. ${ }^{\circ}$ 287). Mesa le enviará un ejemplar de la traducción del Arte poética de Horacio realizada por Afonso. Más adelante, el 22 de octubre de 1884, el propio Mesa desechará la idea de enviarle noticia biográfica del doctoral por carecer de imparcialidad, ya que, escribe (VI, carta n. . 453), "este Sor., a quien me unían lazos de amistad, era también pariente mío" [era sobrino natural de Afonso]. El 22 de marzo del año siguiente, le remite, de mano de un opositor a la cátedra de Historia Natural, la traducción del Ensayo sobre la crítica, de Alexander Pope (VII, carta n. ${ }^{\circ}$ 132). Resulta particularmente extraño que Mesa no le hiciera llegar las memorias del doctoral, que con certeza estuvieran en su mano, pues, según José Álvarez Rixo, Afonso le había dicho a Alejo González de Ara, con quien mantenía correspondencia, que "tenía escrita su vida, la cual él no publicaría pero que la dejaba escrita para que lo hiciesen sus herederos si gustasen" (s.d., VIII). Es muy probable que la prudencia o el pudor hicieran que optara por no entregar el documento al polígrafo.

Pero realmente, según se colige del voluminoso epistolario del polígrafo santanderino, quien le proporcionará mayor documentación es el provisor y vicario general de la Catedral de Las Palmas José López Martín, que además realizará juicios de los dos autores de los que le enviará textos. Así, en marzo de 1888, le remite "un pequeño volumen que contiene algunas composiciones de mis paisanos Viera y Afonso, encarecidamente empeñados uno y otro en ser poetas, invita Minerva como dice Vd. en su "Horacio", con el fin de que lo considere entre "las innumerables curiosidades de su biblioteca"" (IX, carta n. . 151). Tal es la devoción que el remitente profesa por Meléndez Pelayo, que le ruega le envíe un retrato "a fin de que los canarios podamos contemplar y admirar la fisonomía del portentoso joven" (IX, carta n. . 151).

En agosto de 1889, le hará llegar un "curioso folleto de Viera, manuscrito e inédito aún a lo menos que yo sepa" (X, carta n. . $^{115}$ ), escribe el clérigo, y del que no duda de su autenticidad. Asimismo pone en conocimiento del polígrafo que posee un impreso del Viaje a Alemania que le remitirá en el caso de que no conste en su colección. De Graciliano Afonso, continúa López Martín, la biografía que Menéndez Pelayo había buscado le parece que es la realizada en 1866 por un periodista tinerfeño (José Agustín Álvarez Rixo; la biografía del doctoral aparecerá en El ramillete de Canarias, 27, de 21 de febrero de 1867) y promete hacer gestiones para obtenerla. 
Probablemente, será la que le envía en epístola fechada en febrero de 1890 (X, carta n. ${ }^{\circ}$ 335). Sin embargo, al parecer, esta, al igual que "una oda inédita compuesta por Viera y Clavijo con motivo de la victoria obtenida contra Nelson" (X, carta n. ${ }^{\circ}$ 335), se extravió en julio de 1890. Con esa misma fecha envía una "Leyenda Canaria" y una "oda al Teide", además de "una nueva copia del artículo biográfico del Doctoral"4.

En fechas posteriores, el canónigo le enviará “dos cuadernos medio destrozados; uno con la versión del Ensayo sobre la crítica (XI, carta n. . 146, abril 1891) y otro con la del Rizo robado de Pope" (XVIII, carta n. ${ }^{\circ}$ 93, febrero 1905) y la traducción de la Antígona de Sófocles.

El epistolario nos permite conocer, asimismo, hechos como que el polígrafo poseía los Viajes, y López Martín le da noticia de un artículo de A. Dugour del año 1867 sobre la figura del doctoral, autor de quien no oculta su desagrado, por no hablar de menosprecio (X, carta n. 262,12 de diciembre de 1889).

Como se puede comprobar, Menéndez Pelayo realizó bastantes gestiones para obtener noticia del doctoral, gestiones que, por otro lado, fueron fructíferas, como lo demuestra el hecho de que en 1911 asegurara que, "merced al concurso de buenos amigos" -entre los que se encontraba Benito Pérez Galdós (Nuez 1957: 481), alumno del doctoral en el colegio San Agustín-, había podido reunir su obra (1911: 333). ¿Influyeron en Menéndez Pelayo las opiniones que de Afonso le prodigaron los isleños? ¿Influyó en él el liberalismo mental del doctoral?

Las observaciones que Menéndez Pelayo realiza sobre Graciliano Afonso están en la línea de su pensamiento acerca de determinados autores que podemos considerar periféricos, periféricos en tanto que escapan un tanto a las características que fija el "canon oficial"; autores cuyas obras se sitúan en la marginalidad por su temática y por la ideología que dejan traslucir estas. En este sentido resulta interesante ver el discurso que desarrolla Menéndez Pelayo, no exento de violencia hacia quienes considera malos poetas.

Este, en una carta dirigida a José María Pereda (13 de mayo de 1887), sobre los literatos italianos, escribe a propósito de Giambattista Casti:

\footnotetext{
En la epopeya burlesca (única que consentía el prosaísmo de la época) y en los géneros afines mostró verdadera gracia, manchada con frecuentes y escandalosas impurezas de estilo y de lengua, y con otras harto más graves, el famoso Castí [sic], cuyo poema de Gli Animali Parlanti (no quiero hablar de otras obras suyas) ha dado la vuelta a Europa, aunque los italianos jamás le han admitido en el canon de sus obras clásicas. (Menéndez Pelayo 1942: 344)
}

Este juicio crítico sobre uno de los autores que tradujo el doctoral será aplicable a muchos de los escritores y obras que han permanecido fuera del canon de la literatura española; entre los que podríamos citar a Nicolás Fernández de Moratín y su El arte de putear, obra que el santanderino ubica dentro de la "poesía licenciosa, llaga secreta de aquel siglo e indicio no de los menores de la descomposición interior que le trabajaba" (Garrote Bernal 1995: 26). La traducción de Los besos de Juan Segundo realizada por el doctoral le parecía demasiado cruda "en sus expresiones para que pudiese llevar en la portada el nombre del autor y del traductor" (Armas Ayala 1961: 121).

Como se ha señalado, Menéndez Pelayo se refiere en su Historia de las ideas estéticas únicamente a la versión de La Poética de Alexander Pope, si bien también conoce a Afonso como traductor de Virgilio y Anacreonte. Es la influencia de Anacreonte en la lírica española durante parte del XVIII y del XIX la que criticará precisamente Menéndez y Pelayo como síntoma de descomposición moral de una sociedad -en este caso la de Moratín-, criterio que hace extensible a Afonso. 
Esa perspectiva desde la que es analizada la figura del doctoral es en el fondo la que parece permanecer y se va transmitiendo en otros estudiosos. Así, por ejemplo, Josefina Rivera de Álvarez, en su Diccionario de literatura puertorriqueña, recoge las opiniones que vertió Menéndez Pelayo en su Historia de la poesía hispano-americana: Afonso, escribe tomándolo del santanderino, adolece de "cierta excentricidad y pedantería y un gusto candorosamente depravado, que resistió el trato familiar con todos los clásicos antiguos y modernos" (Rivera de Álvarez 1974).

Helmut C. Jacobs dedica un epígrafe al desarrollo del buen gusto en el siglo XIX y en especial a Menéndez Pelayo, del que subraya el uso del concepto del gusto: "para legitimar exclusivamente sus valoraciones estéticas [...] Menéndez Pelayo se considera a sí mismo como un "hombre de gusto" y cree firmemente la existencia de unas reglas reconocidas, obligatorias y en última instancia universales del buen gusto" (2001: 269).

En este sentido, valdría la pena recordar las características que Schiller establece:

El gusto, por sí solo, da armonía a la sociedad, porque otorga armonía al individuo. Todas las restantes formas de representación dividen al hombre, porque se basan exclusivamente en su componente sensible o en su componente espiritual; sólo la representación bella completa el ser del hombre, porque en ella han de coincidir necesariamente sus otras dos naturalezas. (1990: 375)

En cierta manera, el poeta alemán define las líneas generales del pensamiento de Menéndez Pelayo. Para Gadamer, frente a la idea de formación estética propugnada por Schiller, el concepto de gusto se basa en un "baremo de contenido":

\footnotetext{
Lo que es vigente en una sociedad, el gusto que domina en ella, todo esto acuña la comunidad de la vida social. La sociedad elige y sabe lo que le pertenece y lo que no entra en ella. La misma posesión de intereses artísticos no es para ella ni arbitraria ni universal por su idea, sino que lo que crean los artistas y lo que valora la sociedad forma parte en conjunto de la unidad de un estilo de vida y de un ideal de gusto. (1999: 125)
}

Esta sería en principio la justificación del descrédito y, sobre todo, del anonimato al que se le abocó al doctoral. Sin embargo, y en consonancia con el comentario de Gadamer, habría que recordar que uno de los textos de Afonso que conserva Menéndez Pelayo en su biblioteca es la oda Colón, que en definitiva es un canto de alabanza a la emancipación americana.

Colón (2007: 94-108), desde la perspectiva de Menéndez Pelayo, defensor de la idea del viejo imperialismo español, no es una obra "recomendable" para aproximarse al espíritu de lo español. No en vano, en su Historia de los heterodoxos españoles, dedica un apartado a la "Influencia de las sociedades secretas en la pérdida de América". En este, responsabiliza al "evidente y sabido influjo de la heterodoxia enciclopedista, representada por las logias francmasónicas de uno y otro lado de los mares, en la desmembración de nuestro poderoso imperio colonial" (1983: 160).

Es probable que Graciliano Afonso esté incluido en esta heterodoxia que el santanderino conceptuó como nefasta para los designios de España; no es difícil aventurar que el doctoral, en fin, sea condenado al infierno de los malos poetas y su obra, hasta la llegada de Alfonso Armas Ayala, al olvido.

\section{Notas}

1. En su momento, editamos una de las novelas de Casti traducidas por el doctoral (Afonso 2003) y tratamos las novelas que se encuentran en traducción anónima en la Biblioteca Nacional de España (Becerra Bolaños 2004-2005), que trabajó Ángeles Arce (1997). 
2. "entre estas autoridades académicas del Centro [seminario conciliar] existían dos tendencias, de un lado, la ilustración, en cuyo primer plano encontramos la figura de Graciliano Afonso, del otro el tradicionalismo representado por Encina y D. Domingo Huesterlin que luchaban tenazmente contra la indiferencia con que el obispo Verdugo y sus seguidores, según ellos, dejaban correr el error, y que los autores de la más sólida doctrina se faleaban siendo sustituidos por otros que sus mentes matizaban de heréticos" (Hernández Corrales 1997: 116-117).

3. Contrasta esta afirmación con la que hará de la traducción de Iriarte, como comenta Salas Salgado: "El propio Menéndez Pelayo (1952a: II, 248), con su acerada crítica siempre dispuesta, otorga su beneplácito a este prólogo «escrito con la discreción y sano juicio característicos de Iriarte, en que se habla del mérito de Virgilio, de las dificultades que presenta para su interpretación, de la pobreza de las lenguas modernas comparadas con la Latina, de los comentadores y traductores que conviene consultar, etc.»" (2012: 2).

4. "No puedo decirle otro tanto respecto de la Oda de Viera porque se la mandé original" (X, carta n. $\left.{ }^{\circ} 497\right)$.

\section{Bibliografía}

Afonso, Graciliano. 2003. Las bragas de san Grifón. Novela del abate Giambattista Casti en traducción del doctoral de Canarias. Antonio Becerra Bolaños (Ed.). Las Palmas de Gran Canaria: Cabildo de Gran Canaria.

2007. Antología. Antonio Becerra Bolaños (Ed.). Las Palmas de Gran Canaria: Academia Canaria de la Lengua.

Alonso, Ma Rosa. 1952. El poema de Viana. Madrid: CSIC.

Álvarez Barrientos, Joaquín. 2012. "Marcelino Menéndez Pelayo, un escritor clandestino". Ínsula. 790: 2-5.

Álvarez Rixo, José Agustín. s.d. Apuntes biográficos de D. Graciliano Afonso (1775-1861), doctoral de la Santa Catedral de Gran Canaria, copia mecanografiada por D. Julián Fernández Calzadilla. La Orotava (Tenerife): Archivo Álvarez Rixo.

Arce, Ángeles. 1997. "Una de las Novelle Galanti de Casti en una traducción inédita en castellano". Cuadernos de Filología italiana. (4): 151-152.

Armas Ayala, Alfonso. 1961. "Graciliano Afonso, un prerromántico español: V. El bucólico poeta (conclusión)". Revista de historia canaria. 27 (133-134): 63-123.

Becerra Bolaños, Antonio. 2004-2005. "Dos versiones de una novela de Giambattista Casti". Philologica Canariensia. (10-11): 209-224.

Gadamer, Hans-Georg. 1999. Verdad y método, I. (Trad. Ana Agud Aparicio y Rafael de Agapito). Salamanca: Sígueme.

Gil Novales, Alberto (Dir.). 1991. Diccionario Biográfico del Trienio Liberal (DBTL). Madrid: El Museo Universal.

Hernández Corrales, Alejandra. 1997. El Seminario Conciliar del Archipiélago Canario. Estudio histórico-pedagógico. Barcelona: Packagers.

Jacobs, Helmut C. 2001. Belleza y buen gusto / Las teorías de las artes en la literatura española del siglo XVIII. Madrid: Iberoamericana.

Martín Ruiz, Juan Francisco. 1985. Dinámica y estructura de la población de las Canarias Orientales (siglos XIX y XX). Tomo II. Madrid: Excma. Mancomunidad de Cabildos de Las Palmas, Excmo. Cabildo Insular de Gran Canaria. 
Martínez, Marcos. 2003. "Un anacreóntico canario: Graciliano Afonso”. En: Eugenio Padorno y Germán Santana Henríquez (Eds.), 69-144.

Menéndez Pelayo, Marcelino. 1911. Historia de la poesía hispano-americana. Tomo I. Madrid: Victoriano Suárez.

1915. Antología de líricos ingleses y angloamericanos. Madrid.

1942. Estudios y discursos de crítica histórica y literaria, Edición nacional de las obras completas de Menéndez Pelayo. Tomo V. Santander: CSIC.

1983. Historia de los heterodoxos españoles. Regalismo y Enciclopedia. México: Porrúa.

1985. Historia de las ideas estéticas en España, Reseña histórica del desarrollo de las doctrinas estéticas durante el siglo XVIII. México: Porrúa.

1985-1991. Epistolario. Madrid: Fundación Universitaria Española.

Millares Carlo, Agustín y Manuel Hernández Suárez. 1978. Biobibliografía de escritores canarios. Tomo I. Madrid: Excma. Mancomunidad de Cabildos de Las Palmas.

Nuez Caballero, Sebastián de la. 1957. "Menéndez Pelayo y Canarias". Anuario de Estudios Atlánticos. 3: 453-489.

Padorno, Eugenio. 2000. Algunos materiales para la definición de la poesía canaria. Las Palmas de Gran Canaria: Ediciones del Cabildo de Gran Canaria.

2003. "Canariedad e Ilustración: Graciliano Afonso, precursor de una agria polémica". En: Eugenio Padorno y Germán Santana Henríquez (Eds.), 145-164.

Padorno, Eugenio y Germán Santana Henríquez. 2003. Ilustración y pre-romanticismo canarios: una revisión de a obra del doctoral Graciliano Afonso (1775-1861). Las Palmas de Gran Canaria: Universidad de Las Palmas de Gran Canaria y Ayuntamiento de Arucas.

Pope, Alexander. 1840. Ensayo sobre la Crítica de Alejandro Pope, traducido del inglés con anotaciones, Trinidad, 1836. Collina: Imprenta de Las Palmas a C.D.M.

1851. El rizo robado, traducido del castellano por el traductor del Ensayo de la Crítica, del mismo autor. Las Palmas de Gran Canaria.

Rivera de Álvarez, Josefina. 1974. Diccionario de literatura puertorriqueña. (2a ed.). San Juan de Puerto Rico: Instituto de cultura puertorriqueña.

Salas Salgado, Francisco. 2012. "Eneida de Virgilio, en la traducción de Tomás de Iriarte (1787)". Recuperado de: http://www.cervantesvirtual.com/obra/eneida-de-virgilio-enla-traduccion-de-tomas-de-iriarte-1787/ Consulta: 15 de septiembre de 2012.

Sánchez Pesquera, M. 1915. Antología de líricos ingleses y angloamericanos. Tomo 234. Madrid: Librería de Perlado.

Schiller, Friedrich. 1990. Kalias. Cartas sobre la educación estética del hombre. Madrid: Anthropos, Ministerio de Educación y Ciencia. 